\title{
Evaluating the impact of different pipe arrangements on the thermal performance of thermo-active piles
}

\author{
Ryan Y. W. Liu ${ }^{1, *}$, Eleonora Sailer ${ }^{1}$, David M. G. Taborda ${ }^{1}$, and David M. Potts ${ }^{1}$ \\ ${ }^{1}$ Department of Civil and Environmental Engineering, Skempton Building, Imperial College London, London, United Kingdom
}

\begin{abstract}
Thermo-active piles are widely utilised for low carbon heating and cooling, and their uses are further encouraged in cities where there are obligations for developments larger than a certain threshold to generate a portion of their estimated energy use on site in a renewable manner. It is therefore important to model accurately the thermal performance of the designed thermo-active piles to ensure that such obligations are complied with. In this paper, the thermal performance of a thermo-active pile is quantified by the evolution with time of the power that can be harnessed from the pile, obtained from 3D thermo-hydro-mechanically coupled finite element analyses which include the simulation of a hot fluid flowing through heat exchanger pipes. Different pipe arrangements are considered in this study, in order to demonstrate the potential gains in efficiency arising from the installation of multiple U-loops within the pile. Furthermore, detailed analysis of the heat fluxes resulting from pipe-pile-soil interaction is carried out, illustrating the contribution of the different components of the system (concrete, near-field and far-field) to the overall storage of thermal energy.
\end{abstract}

\section{Introduction}

Thermo-active piles differ from conventional piles in a way that heat exchanger pipes are embedded within them, which allow the circulation of a hot or cold fluid in order to promote the exchange of heat with the ground. The cooled or heated fluid can then be used for cooling or heating in a building via a heat pump. The fact that thermo-active piles function both as a ground source heat pump (GSHP) system to provide low carbon heating and cooling and as a foundation to provide structural stability justifies their growing popularity in recent years. Increasingly stringent environmental and sustainability targets, which require a proportion of energy demand to be produced on-site by renewable means (e.g. [1]), further encourage the use of thermo-active piles, as these are often the only viable option to produce renewable energy in dense urban settings. In order to ensure that such an obligation is complied with during the design of thermoactive piles, it is important to model its thermal performance accurately, which is quantified in this paper by the evolution of power with time that can be harnessed from the pile, as well as the storage of energy (which is related to the temperature field) in different components of the system, namely in the pile itself, near-field and farfield in the soil.

In order to estimate the evolution of temperature in the ground due to a borehole heat exchanger, which has a much larger aspect ratio (pile length to diameter ratio) than a thermo-active pile, [2] proposed the use of temperature response functions (G-functions). [3-5] then provided new G-functions for thermo-active piles, which can account for their transient behaviour and the energy storage within the pile. However, the use of such Gfunctions requires the knowledge of the heating and cooling power associated with a given thermo-active pile, despite the fact that this quantity varies with time and cannot be determined accurately before installation, as it is dependent on a number of factors, such as the temperature of the circulated fluid, initial ground temperature, pile and soil thermal conductivities, etc.

In this paper, the operation of a thermo-active pile is simulated by conducting fully coupled 3D thermo-hydromechanical (THM) finite element (FE) analyses, which include the explicit simulation of a geothermal fluid (in the present case, water) circulating through heat exchanger pipes, using the Imperial College Finite Element Program (ICFEP, [6, 7]). This provides an accurate approach to simulating the behaviour and response of a thermo-active pile and allows the power with time, as well as the temperature field (and hence energy storage) both within and around the pile to be determined. Different pipe arrangements can be adopted within a thermo-active pile, with the cases of single Uloop (1U) and triple U-loop (3U) being considered in this paper to quantify the improvement in thermal performance associated to the increase in the number of U-loops installed in a thermo-active pile.

\section{Fully coupled 3D THM FE analyses}

A thermo-active pile with a diameter of $900 \mathrm{~mm}$ and a length of $25 \mathrm{~m}$ is considered in this study. Two fully coupled 3D THM FE analyses are conducted, in which the circulation through heat exchanger pipes of a hot fluid (assumed to be water) $20^{\circ} \mathrm{C}$ above the initial ground

\footnotetext{
* Corresponding author: ryl13@imperial.ac.uk
} 
temperature is explicitly modelled. The first analysis (Analysis 1) adopts a $1 \mathrm{U}$ pipe arrangement, with the second analysis (Analysis 2) adopting a $3 U$ pipe arrangement. The pipes have an internal diameter of $26 \mathrm{~mm}$, which carries fluid at a velocity of $0.2 \mathrm{~m} / \mathrm{s}$, and a concrete cover of $70 \mathrm{~mm}$ is adopted, following the characteristics of the thermal response test reported by [8]. Figure 1 illustrates the arrangement of pipes and the way water is circulated for both analyses.

\subsection{Stratigraphy and FE mesh}

The stratigraphy adopted in this study is an idealised profile with a single layer of London clay, which is similar to that considered in $[9,10]$. The discretised soil domain is $64 \mathrm{~m}$ deep and $80 \mathrm{~m}$ in diameter and illustrations of the adopted mesh are shown in Figures 2 and 3. Note that, while only half of the mesh is shown, the analyses were carried out with the full mesh given the lack of symmetry (for the case of $3 \mathrm{U}$ ) introduced by the circulation of the fluid through the heat exchangers.

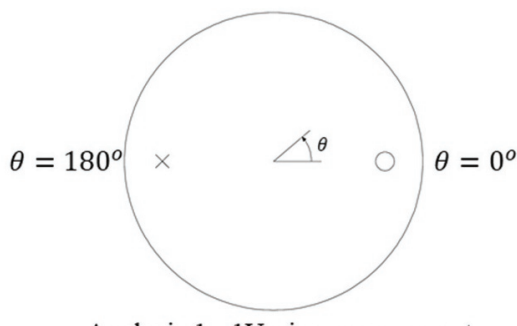

Analysis 1 - 1U pipe arrangement

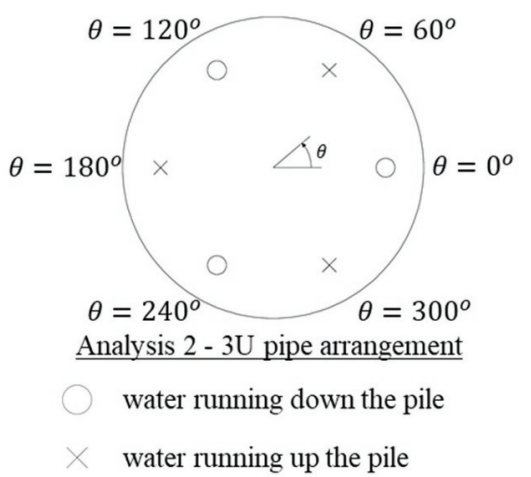

Fig. 1. Pipe arrangements and modelled water circulation for both analyses.

Elements representing the pile and London clay are discretised using 20-noded isoparametric hexahedra elements, while the heat exchanger pipes are discretised using 1D 3-noded bar elements [11]. In all cases, there are three displacement and one temperature degrees of freedom at each node. For elements discretising the London clay and the heat exchanger pipes, one additional pore water pressure degree of freedom also exists at corner/end nodes. Note that the pipes are surrounded by a thermally enhanced material (TEM), as proposed by [12], in order to correctly model the amount of heat being transferred from the pipes to the pile, and that the diameter of the TEM corresponds to the internal diameter of the pipes (i.e. $26 \mathrm{~mm}$ ).

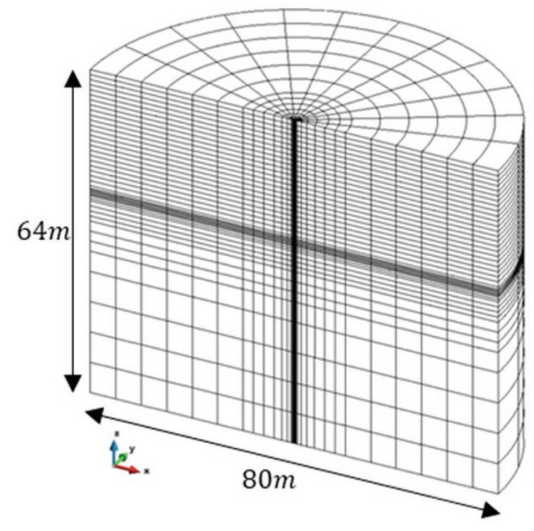

Fig. 2. Half of the FE mesh adopted for both analyses.

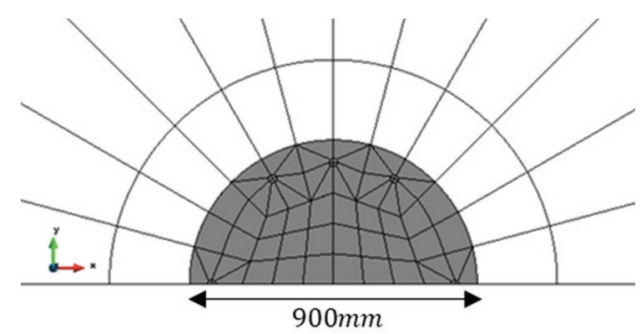

Fig. 3. Plan view of half of the zoomed-in FE mesh detailing the pile (shaded in grey).

\subsection{Initial and boundary conditions}

The adopted initial conditions for temperatures, pore water pressures and coefficient of earth pressure at-rest $\left(K_{0}\right)$ are based on those adopted in $[10,13]$. The initial ground temperature is assumed to be at $19.5^{\circ} \mathrm{C}$, while an underdrained initial pore water pressure (Figure 4(a)) and $K_{0}$ profiles typical of ground conditions in London are adopted (Figure 4(b)).

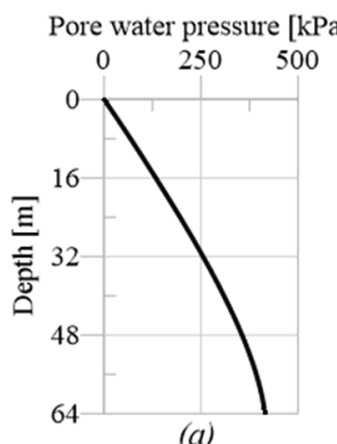

(a)

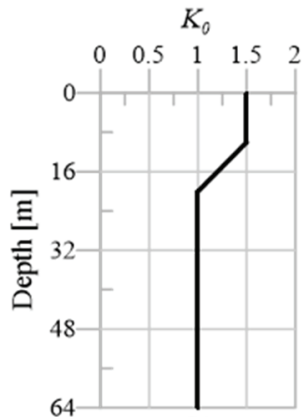

(b)
Fig. 4. (a) Initial underdrained pore water pressure profile and (b) Initial $K_{0}$ profile.

In terms of displacement boundary conditions, the far cylindrical boundary is restricted from moving in the radial direction, while the bottom boundary is restricted from moving in all directions. Prescribed hydraulic boundary conditions are such that there is no change in pore water pressure at both the top and bottom boundaries and no water flow is allowed across the far cylindrical boundary. Lastly, thermal boundary conditions ensuring that there is no change in temperature from the initial 
ground temperature are applied at all boundaries, except for the top of the pile which is modelled as adiabatic.

\subsection{Material models and properties}

Table 1. Material properties for London Clay.

\begin{tabular}{|c|c|}
\hline \multicolumn{2}{|c|}{ Mohr-Coulomb strength properties } \\
\hline$c^{\prime}$ & $5.0 \mathrm{kPa}$ \\
\hline$\phi^{\prime}$ & $25.0^{\circ}$ \\
\hline$\psi^{\prime}$ & $12.5^{\circ}$ \\
\hline \multicolumn{2}{|c|}{ Small-strain stiffness properties } \\
\hline$G_{r e f}$ & $51743.55 \mathrm{kPa}$ \\
\hline$p_{\text {ref }}^{\prime}$ & $100 \mathrm{kPa}$ \\
\hline$m_{G}$ & 1.0 \\
\hline$m_{K}$ & 1.0 \\
\hline$a$ & 0.000056 \\
\hline$b$ & 0.9 \\
\hline$R_{G, \min }$ & 0.06450 \\
\hline$G_{\min }$ & $2667 \mathrm{kPa}$ \\
\hline$K_{r e f}$ & $26692.73 \mathrm{kPa}$ \\
\hline$r$ & 0.000127 \\
\hline$s$ & 1.8 \\
\hline$R_{K, \text { min }}$ & 0.13275 \\
\hline$K_{\min }$ & $5000 \mathrm{kPa}$ \\
\hline Thermal and thermo-mechanical properties \\
\hline$\alpha_{S}$ & $1.7 \times 10^{-5} \mathrm{~m} / \mathrm{mK}$ \\
\hline$\alpha_{f}$ & $6.9 \times 10^{-5} \mathrm{~m} / \mathrm{mK}$ \\
\hline$K_{f}$ & $2.2 \mathrm{GPa}$ \\
\hline$\rho C_{p}$ & $1820 \mathrm{~kJ} / \mathrm{m} \mathrm{K}$ \\
\hline$\lambda$ & $1.79 \times 10^{-3} \mathrm{~kW} / \mathrm{mK}$ \\
\hline \multicolumn{2}{|c|}{ Hydraulic properties } \\
\hline$k_{0}$ & $1.0 \times 10^{-10} \mathrm{~m} / \mathrm{s}$ \\
\hline$B$ & $0.0023 / \mathrm{kPa}$ \\
\hline \multicolumn{2}{|c|}{} \\
\hline
\end{tabular}

Table 2. Material properties for the concrete pile.

\begin{tabular}{|c|c|}
\hline \multicolumn{2}{|c|}{ Mechanical properties } \\
\hline$E$ & $40 \times 10^{6} \mathrm{kPa}$ \\
\hline$\mu$ & 0.3 \\
\hline \multicolumn{2}{|c|}{ Thermal and thermo-mechanical properties } \\
\hline$\alpha_{s}$ & $8.5 \times 10^{-6} \mathrm{~m} / \mathrm{mK}$ \\
\hline$\rho C_{p}$ & $1920 \mathrm{~kJ} / \mathrm{m}^{3} \mathrm{~K}$ \\
\hline$\lambda$ & $2.33 \times 10^{-3} \mathrm{~kW} / \mathrm{mK}$ \\
\hline
\end{tabular}

Table 3. Material properties for the heat exchanger pipes.

\begin{tabular}{|c|c|}
\hline \multicolumn{2}{|c|}{ Linear material properties } \\
\hline$E$ & $1 \times 10^{3} \mathrm{kPa}$ \\
\hline Thermal and thermo-mechanical properties \\
\hline$\alpha_{s}$ & $8.5 \times 10^{-6} \mathrm{~m} / \mathrm{mK}$ \\
\hline$\rho C_{p}$ & $4190 \mathrm{~kJ} / \mathrm{m}^{3} \mathrm{~K}$ \\
\hline$\lambda$ & $6.0 \times 10^{-4} \mathrm{~kW} / \mathrm{mK}$ \\
\hline
\end{tabular}

The London clay is modelled as nonlinear elasto-plastic, with a Mohr-Coulomb failure criterion determining its strength and the Imperial College Small Strain Stiffness (IC.G3S) model [14] being used for its pre-yield behaviour. A nonlinear permeability model given by $k=$ $k_{0} e^{-B p^{\prime}}$, where $k$ is permeability, $k_{0}$ and $B$ are model parameters and $p^{\prime}$ is mean effective stress, is adopted to model the hydraulic behaviour of London clay. Table 1 reports all the material properties adopted for the London clay, which are adopted from $[13,15]$. The concrete thermo-active pile, heat exchanger pipes and the TEM surrounding the pipes are all modelled as linear elastic. Tables 2 and 3 show all the material properties adopted for the concrete pile and pipes respectively, which are identical to those adopted by [10]. Note that the material properties adopted for the TEM are identical to those used for the concrete pile, except that a thermal conductivity $(\lambda)$ of $4.5 \times 10^{-3} \mathrm{~kW} / \mathrm{mK}$ is adopted, which is obtained based on an empirical relationship with the internal pipe diameter, and a volumetric heat capacity $\left(\rho C_{p}\right)$ of $1 \mathrm{~kJ} / \mathrm{m}^{3} \mathrm{~K}$ is used [12]. The volumetric heat capacity of water $\left(\rho C_{w}\right)$ is taken as $4190 \mathrm{~kJ} / \mathrm{m}^{3} \mathrm{~K}$.

In Tables 1 to $3, c^{\prime}$ is cohesion, $\phi^{\prime}$ is the angle of shearing resistance, $\psi^{\prime}$ is angle of dilation, $G_{r e f}$ is the maximum shear modulus at reference mean effective stress $\left(p_{\text {ref }}^{\prime}\right), m_{G}$ and $m_{K}$ are parameters defining the dependence of elastic stiffness on mean effective stress, $a, b, r$ and $s$ are stiffness degradation parameters, $R_{G, \min }$ is the minimum normalised value of the tangent shear modulus, $G_{\text {min }}$ is the minimum shear modulus, $K_{r e f}$ is the maximum bulk modulus at reference mean effective stress, $R_{K, \min }$ is the minimum normalised value of the tangent bulk modulus, $K_{\min }$ is the minimum bulk modulus, $\alpha_{s}$ is the linear coefficient of thermal expansion of the soil skeleton, $\alpha_{f}$ is the linear coefficient of thermal expansion of the pore fluid, $K_{f}$ is the bulk modulus of the pore fluid, $E$ is the Young's modulus and $\mu$ is the Poisson's ratio.

\subsection{Modelling procedure}

In the analyses, the thermo-active pile, which is modelled as wished-in-place, is first loaded to $2900 \mathrm{kN}$ (which corresponds to a factor of safety of 2.6 applied to its ultimate capacity, as determined using the $\alpha$-method with $\alpha=0.5$ and $S_{u}=60+8 z$, where $z$ is the distance to the top of the London Clay) by applying a vertical stress at the top of the pile. Subsequently, full dissipation of excess pore water pressures is allowed before heat injection for a duration of 5 months is simulated within this study. A prescribed temperature boundary condition of $39.5^{\circ} \mathrm{C}$ is applied at the inlet node of the heat exchanger pipe(s), within which water was circulated at a flow rate of $1.032 \times 10^{-4} \mathrm{~m}^{3} / \mathrm{s}$. The water flow is achieved by applying a water pressure differential between the pipe inlet(s) and outlet(s). At the pipe outlet(s), a coupled thermo-hydraulic boundary condition [16] is prescribed to remove the energy corresponding to the water flowing out of the mesh. Lastly, the Petrov-Galerkin FE method [17] is adopted for the pipes, together with the use of appropriate time-steps, as the conventional Galerkin FE method causes numerical oscillations when an advectiondominated heat flux is modelled.

\section{Results and discussion}

In this study, the thermal performance of the thermoactive pile is quantified by the evolution with time of the system's power (i.e. rate of energy transfer to the pile), as 
well as of the energy stored within different parts of the system with time.

\subsection{Evolution of power with time}

The rate of energy transfer between the heat exchanger pipes and the pile at a time instant $t, P(t)$ (in $W$ ), can be evaluated using Equation (1):

$$
P(t)=\rho C_{w} \cdot Q \cdot\left(T_{\text {in }}(t)-T_{\text {out }}(t)\right)
$$

where $Q$ is the flow rate of the fluid, $T_{\text {in }}(t)$ is the temperature of fluid entering the pile at $t$ and $T_{\text {out }}(t)$ is the temperature of fluid leaving the pile at $t$. The evolution of $P(t)$ with time, normalised by the length of pile, is shown in Figure 5.

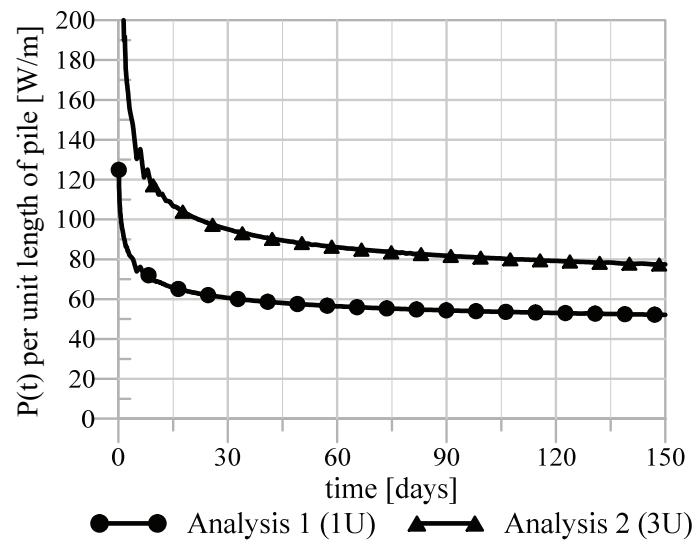

Fig. 5. Evolution of $P(t) / L$ with time for both analyses.

During the early stages of the analyses, the power is large, as a result of the large thermal gradient between the hot pipe and the cold pile. As time progresses, the power reduces significantly and, by the end of 5 months, it has practically reached a constant value. This is due to the overall increase in temperature of the pile, which leads to the reduction of the thermal gradient between the pipe and the surrounding concrete. In effect, in the long-term, a steady thermal gradient is established as the rate of energy transfer from the pipes into the pile approaches the rate of energy transfer from the pile into its surrounding soil. Note that this pattern of power evolution with time is also observed in $[18,19]$.

It can be seen in Figure 5 that increasing the number of U-loops from one to three increases both the short-term and long-term power. However, it should be appreciated that, while the number of U-loops in Analysis 2 is triple of that in Analysis 1, the power of the pile at $t=$ 150 days only yields a $48 \%$ increase, with $P(t=$ 150 days) per unit pile length being $52 \mathrm{~W} / \mathrm{m}$ for Analysis 1 and $77 \mathrm{~W} / \mathrm{m}$ for Analysis 2. This finding is in agreement with the conclusions presented in $[18,20,21]$.

\subsection{Storage of energy}

In this section, the thermo-active pile-soil system is divided into different parts, in which the change in energy content with time is evaluated in order to quantify the relative contribution of different components of the system towards the storage of energy at different timescales. Six sections were chosen in this study:

1. The pile

2. The $250 \mathrm{~mm}$-thick soil annulus around the pile

3. The next $600 \mathrm{~mm}$-thick soil annulus

4. The next $1100 \mathrm{~mm}$-thick soil annulus

5. The next $1600 \mathrm{~mm}$-thick soil annulus

6. The rest of the soil

The storage of energy, or change in energy content of section $i, \Delta E_{i}(t)$ (in $J$ ), can be evaluated using Equation (2):

$$
\Delta E_{i}(t)=\rho C_{p, i} \cdot V_{i} \cdot \Delta T_{a v, i}(t)
$$

where $\rho C_{p, i}$ is the volumetric heat capacity of the material in section $i, V_{i}$ is its volume and $\Delta T_{a v, i}(t)$ is the corresponding average change in temperature.

Figures 6 and 7 show the average changes in temperature in the six aforementioned sections of the pilesoil system for Analysis 1 and 2 respectively. It can be observed that, as expected, the largest changes in temperature take place at the pile, which is the section closest to the pipes (i.e. the heat sources). As the distance from the pipes increases, the maximum average change in temperature that is reached progressively reduces, reaching negligible values at the far-field (i.e. the 'rest of soil' section). Moreover, the results show that when a 3U pipe arrangement is used (Figure 7), the soil section that is adjacent to the pile (i.e. section 2) is heated up by $13.9^{\circ} \mathrm{C}$ at $t=150$ days (i.e. $\approx 70 \%$ of the inlet temperature). Clearly, such an extent of heating of the soil could potentially lead to thermally-induced consolidation or thermal failure [22]. Comparing Figures 6 and 7, the average change in temperature in all sections are larger when the number of U-loops increases, which is expected as a larger amount of energy is being transferred into the pile (see Figure 5).

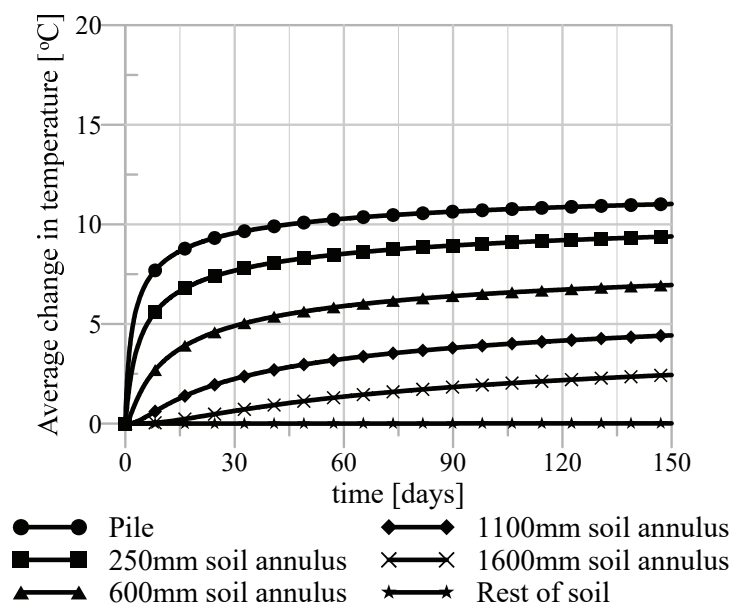

Fig. 6. Average change in temperature in different sections for Analysis 1. 


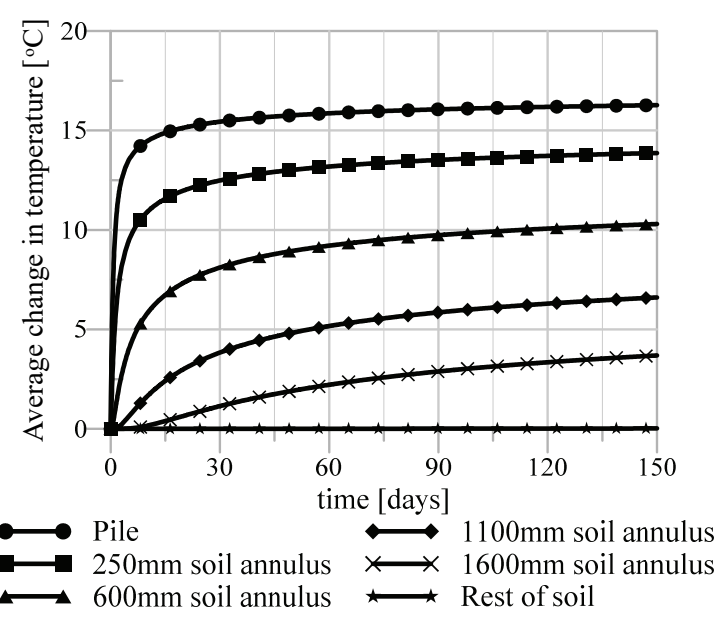

Fig. 7. Average change in temperature in different sections for Analysis 2.

It should be noted that, in the simulated case, the energy stored in the entire system (i.e. $\left.\sum_{i} \Delta E_{i}(t)\right)$ at any given time is always smaller than the total amount of energy $\left(H(t)=\int P(t) d t\right)$ that has been transferred into the system, due to losses through the top boundary of the mesh which is maintained at a constant temperature. Comparing the transferred energy with the stored energy shows that losses amount to about $16 \%$ for Analysis 1 and $18 \%$ for Analysis 2 at $t=150$ days. However, it should be noted that there is a significant uncertainty in the modelling of this energy loss, as it is highly dependent on the boundary conditions, e.g. the ground surface is subjected to temperature variations throughout the year, the pile is constructed under a building, etc. As a result, the contribution of each component in terms of energy storage is measured in this paper using $\Delta E_{i}(t) / \sum_{i} \Delta E_{i}(t)$, which ignores the contribution of the heat losses by normalising $\Delta E_{i}(t)$ by the total stored energy $\left(\sum_{i} \Delta E_{i}(t)\right)$ instead of the transferred energy $(H(t))$.

Figures 8 and 9 show the evolutions with time of the normalised stored energy in each of the six aforementioned pile/soil sections for Analysis 1 and 2, respectively. It can be observed that, although a significantly larger amount of energy is transferred into the system when a $3 \mathrm{U}$ pipe arrangement is used (Figure $5)$, when the energy stored in different sections is normalised by the total amount of energy in the system, the patterns obtained for both analyses are very similar. This suggests that the transient storage of energy in different parts of the system is relatively independent of the amount of energy that is being transferred into the system, with the effect of other factors such as pile dimensions, relative thermal conductivities between the pile concrete and the soil requiring further investigation. The patterns shown in Figures 8 and 9 indicate that, when heat injection commences, more than $80 \%$ of the energy is initially stored within the pile. As time progresses, energy is transferred from the pile outwards into the soil, with the section that contributes most to energy storage moving outwards from the pile with time. At $t=$ 150 days, around $50 \%$ of the total energy is stored in the far-field soil, while the pile only contributes to about $2 \%$ of the total energy stored within the system. It should be noted that the large volume of the far-field soil allows it to store a significant amount of energy without noticeable change in temperature (see Figures 6 and 7), confirming the need to consider the entire pile-soil system when evaluating long-term energy storage.

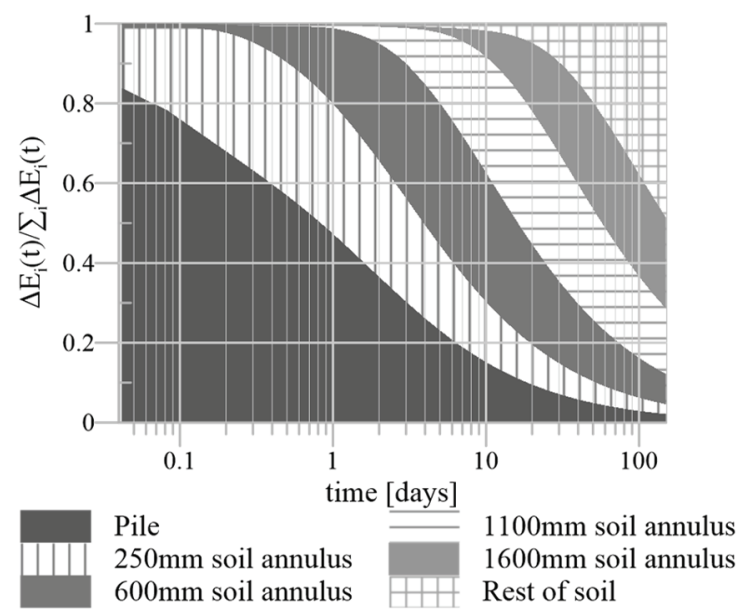

Fig. 8. Evolution of $\Delta E_{i}(t) / \sum_{i} \Delta E_{i}(t)$ with time for Analysis 1 (1U).

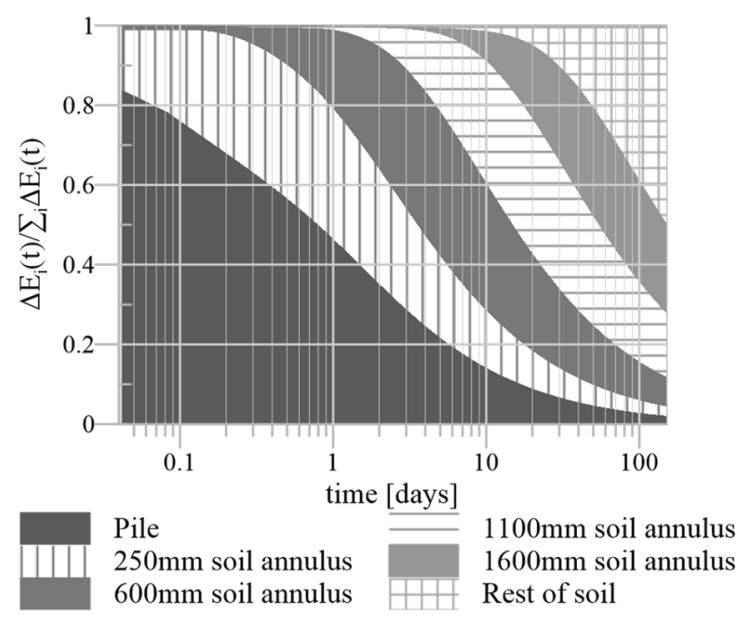

Fig. 9. Evolution of $\Delta E_{i}(t) / \sum_{i} \Delta E_{i}(t)$ with time for Analysis 2 (3U).

\section{Conclusions}

In this study, two fully coupled 3D THM FE analyses are conducted to simulate 5 months of heat injection into a thermo-active pile with $1 \mathrm{U}$ (Analysis 1) and 3U (Analysis 2) pipe arrangements. The analyses simulate explicitly the circulation of geothermal fluid through heat exchanger pipes embedded within the thermo-active pile. The consideration of two different pipe arrangements (1U and $3 \mathrm{U})$ allows the quantification of the potential improvements in thermal performance of a thermo-active pile when the number of U-loops increases.

The power of the thermo-active pile is found to be large shortly after heat injection commences, dropping rapidly in the first month and reaching a relatively constant value within the first 5 months. It is also found that, as expected, both the short- and long-term thermal 
power that can be harnessed from the thermo-active pile increase with the number of U-loops. However, increases in power are not directly proportional to the number of Uloops, since tripling their number only results in a $48 \%$ increase in power after 5 months of heat injection.

By calculating average temperature changes in the six different sections within the pile-soil system that have been chosen in this study, it has been revealed that the two analyses are characterised by almost identical patterns of proportions of energy stored, despite the fact that a larger amount of energy is transferred into the system in Analysis 2. This suggests that the storage of energy in different sections of the system is independent on the amount of energy being transferred into the system. Therefore, the results presented in this paper allow a prediction of where the majority of energy transferred into the system is stored at a given time instant, provided that other parameters such as pile dimensions and thermal conductivities are similar to those considered in this study. In effect, it can be observed that most of the energy is stored within the pile during the first days of heat injection. With time, the section that contributes most to the storage of energy moves away from the pile, and that after five months of heat injection, only $2 \%$ of the total energy is stored within the pile, while around half of the energy is stored in the far-field soil (defined arbitrarily in this paper as the soil at a distance from the pile greater than $3.55 \mathrm{~m}$ ), demonstrating the importance of modelling the entire pile-soil system when evaluating the long-term thermal performance of thermo-active piles.

To conclude, it is determined that increasing the number of U-loops in a thermo-active pile is beneficial in terms of thermal performance, as this allows the pile to operate at a larger power. This does not appear to influence the patterns of energy storage in the pile-soil system, though more U-loops result in higher operating temperatures in the soil immediately adjacent to the pile which, if excessively heated, may lead to substantial thermo-hydro-mechanical interactions that need to be accounted for in the thermo-mechanical design of thermoactive piles.

The first author is funded by the Imperial College President's $\mathrm{PhD}$ Scholarship and the Engineering and Physical Sciences Research Council (EPSRC) (grant number: EP/R512540/1) and the second author wishes to acknowledge the support from the Department of Civil and Environmental Engineering of Imperial College London through the Skempton Scholarship.

\section{References}

1. Merton Council. Sustainable design and construction evidence base: Climate change in the planning system. Merton Council. (2010)

2. P. Eskilson. Thermal analysis of heat extraction boreholes [PhD thesis]. Sweden: University of Lund; (1987).

3. M. Li, A.C.K. Lai. New temperature response functions ( $\mathrm{G}$ functions) for pile and borehole ground heat exchangers based on composite-medium linesource theory. Energy. 38(1):255-63. (2012)
4. F. Loveridge, W. Powrie. Temperature response functions (G-functions) for single pile heat exchangers. Energy. 57:554-64. (2013)

5. M.A. Pagola, R.L. Jensen, S. Madsen, S.E. Poulsen. Method to obtain g-functions for multiple precast quadratic pile heat exchangers. Aalborg University. Report No.: DCE Technical Reports, No. 243 Contract No.: DCE Technical Reports, No. 243. (2018)

6. D.M. Potts, L. Zdravkovic. Finite element analysis in geotechnical engineering: theory. London: Thomas Telford Publishing; (1999).

7. D.M. Potts, L. Zdravkovic. Finite element analysis in geotechnical engineering: application. London: Thomas Telford Publishing; (2001).

8. F. Loveridge, W. Powrie, D. Nicholson. Comparison of two different models for pile thermal response test interpretation. Acta Geotech. 9(3):367-84. (2014)

9. K.A. Gawecka, D.M. Potts, D.M.G. Taborda, W. Cui, L. Zdravkovic, Effects of transient phenomena on the behaviour of thermo-active piles. 1st International Conference on Energy Geotechnics, ICEGT 2016. (2016)

10. R.Y.W. Liu, D.M.G. Taborda, K.A. Gawecka, W. Cui, D.M. Potts, Computational study on the effects of boundary conditions on the modelled thermally induced axial stresses in thermo-active piles. XVII European Conference on Soil Mechanics and Geotechnical Engineering; Reykjavik, Iceland. (2019)

11. K.A. Gawecka, D.M. Potts, W. Cui, D.M.G. Taborda, L. Zdravković. A coupled thermo-hydro-mechanical finite element formulation of one-dimensional beam elements for three-dimensional analysis. Comput Geotech. 104:29-41. (2018)

12. K.A. Gawecka, D.M.G. Taborda, D.M. Potts, E. Sailer, W. Cui, L. Zdravkovic. Finite element modelling of heat transfer in ground source energy systems with heat exchanger pipes. Int J Geomech (in press). (2019)

13. F.C. Schroeder, D.M. Potts, T.I. Addenbrooke. The influence of pile group loading on existing tunnels. Geotechnique. 54(6):351-62. (2004)

14. D.M.G. Taborda, D.M. Potts, L. Zdravković. On the assessment of energy dissipated through hysteresis in finite element analysis. Comput Geotech. 71:180-94. (2016)

15. K.A. Gawecka, D.M.G. Taborda, D.M. Potts, W. Cui, L. Zdravković, M.S. Haji Kasri. Numerical modelling of thermo-active piles in London Clay. Proc Inst Civ Eng Geotech Eng. 170(3):201-19. (2017)

16. W. Cui, K.A. Gawecka, D.M. Potts, D.M.G. Taborda, L. Zdravković. Numerical analysis of coupled thermo-hydraulic problems in geotechnical engineering. Geomech Energy Environ. 6:22-34. (2016)

17. W. Cui, K.A. Gawecka, D.M. Potts, D.M.G. Taborda, L. Zdravković. A Petrov-Galerkin finite element method for 2D transient and steady state highly advective flows in porous media. Comput Geotech. 100:158-73. (2018) 
18. H.-w. Lu, X. Jin, G. Jiang, W.-q. Liu. Numerical Analysis of the Thermal Performance of Energy Pile with U-Tube. Energy Procedia. 105:4731-7. (2017)

19. Jalaluddin, A. Miyara, K. Tsubaki, S. Inoue, K. Yoshida. Experimental study of several types of ground heat exchanger using a steel pile foundation. Renewable Energy. 36(2):764-71. (2011)

20. F. Cecinato, F.A. Loveridge. Influences on the thermal efficiency of energy piles. Energy. 82:102133. (2015)

21. J. Gao, X. Zhang, J. Liu, K. Li, J. Yang. Numerical and experimental assessment of thermal performance of vertical energy piles: An application. Appl Energy. 85(10):901-10. (2008)

22. K.A. Gawecka. Numerical analysis of geothermal piles [PhD Thesis]. London: Imperial College London; (2017). 